This item was submitted to Loughborough's Research Repository by the author.

Items in Figshare are protected by copyright, with all rights reserved, unless otherwise indicated.

\title{
Developing a methodology for aligning supply chains from a relationships
} perspective

\section{PLEASE CITE THE PUBLISHED VERSION}

\section{PUBLISHER}

(C) IMechE / Professional Engineering Publishing

\section{VERSION}

VoR (Version of Record)

\section{LICENCE}

CC BY-NC-ND 4.0

\section{REPOSITORY RECORD}

Dani, Samir, Neil D. Burns, and C.J. Backhouse. 2019. "Developing a Methodology for Aligning Supply Chains from a Relationships Perspective". figshare. https://hdl.handle.net/2134/4569. 
This item was submitted to Loughborough's Institutional Repository (https://dspace.lboro.ac.uk/) by the author and is made available under the following Creative Commons Licence conditions.

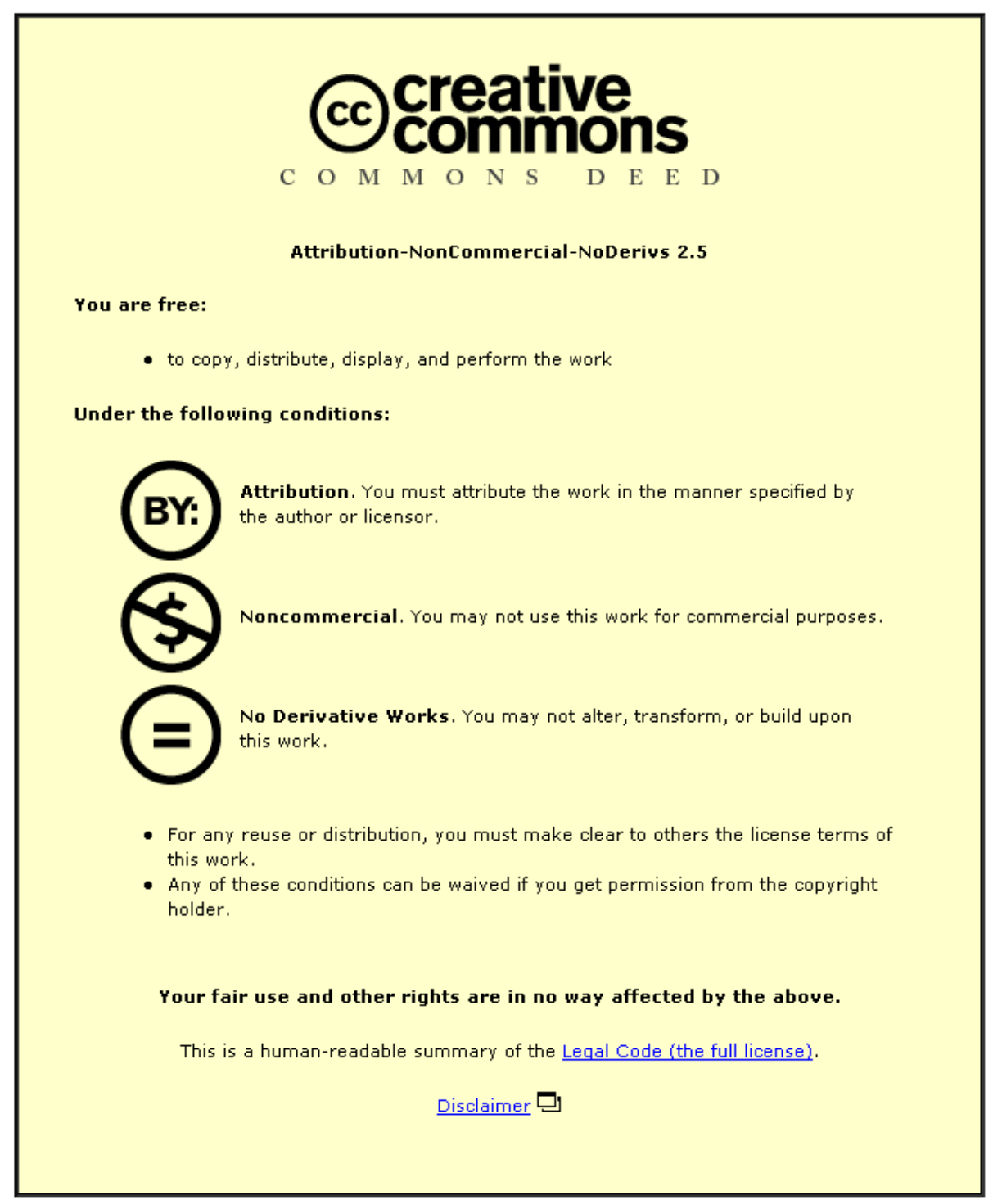

For the full text of this licence, please go to: http://creativecommons.org/licenses/by-nc-nd/2.5/ 


\title{
Developing a methodology for aligning supply chains from a relationships perspective
}

\author{
S S Dani*, N D Burns, and C J Backhouse \\ Wolfson School of Mechanical and Manufacturing Engineering, Loughborough University, Loughborough, UK
}

The manuscript was received on 6 May 2005 and was accepted after revision for publication on 25 January 2006.

DOI: $10.1243 / 09544054 J E M 378$

\begin{abstract}
The research presented in this paper has focussed on exploring buyer-supplier relationships from a human perspective. The research has been successful in exploring issues affecting buyer-supplier relationships. A methodology for aligning supply chains by taking into account human issues has been proposed. The methodology consists of a relationship framework that is used for studying buyer-supplier relationships on a macro-level based on the levels of satisfaction that the entities have with each other. Since high levels of dissatisfaction lead to various change-inducing transactions or game-like behaviour between the entities, the framework identifies the status of the relationship, and can be used to gauge what is going to happen to it, once the transaction is over. The concepts of transactional analysis and the tools associated with it, namely drama triangle analysis and structural modelling, are useful in studying the dynamics of the transactions from the human perspective and also from a psychological perspective.
\end{abstract}

Keywords: supply chains, buyer-supplier relationships, transactional analysis, drama triangle analysis, structural modelling

\section{RESEARCH CONTEXT}

Some quotes from various sources follow in order to draw attention to the fact that there are many dynamics involved in the buyer-supplier relationship scenario. There has already been much research conducted and more is being conducted in the field of buyer-supplier relationships, mainly by studying partnership or collaborative techniques or alternatively the negative issues of power and unethical behaviour. The present authors think that the premise presented in this section warrants further research in order to understand whether there are any other issues involved in buyer-supplier relationships, and primarily whether there is any other reason for organizations or individual humans to show the behaviour as depicted in some examples below. Also, if there is a tendency for such behaviour to be a part and parcel of these relationships, then, in order that supply chain entities transact and

*Corresponding author: Wolfson School of Mechanical and Manufacturing Engineering, Loughborough University, Loughborough, Leicestershire LE11 3TU, UK. email: S.Dani@ lboro.ac.uk conduct better relationships with each other there should be a process of aligning their perceptions and needs from the relationship in order to function better.

'It's another example of the multiple CEO's showing great sympathy for the farmers' plight, yet purchasing executives further down the supermarket teams seem to be making their own rules.' [1].

'Some of the more junior buyers seem to think, for example, we can magic up one million extra chickens in a moment. The poultry industry is not like that.' [1].

'... from farmyard to kitchen, a few giant supermarket chains increasingly dominate our lives.' [1].

These quotes depict the fact that the relationships between buyers and suppliers are subjected to many factors, namely power, trust, human behaviour, dominance, etc., and in order to study these relationships all these factors have to be looked at in a holistic perspective. Also, in research conducted to study ethical issues in global buyer-supplier relationships, Carter [2] found that unethical practices conducted by both buyers and suppliers strained these already complex relationships further, leading to trust deterioration and relationship break-ups. 
It is evident that human behaviour is a major factor in these relationships. The behaviour shown by individual human beings is very important to the relationship. It also raises the question of whether it is only the human behaviour affecting these relationships or whether it is the organization as a whole also showing some behaviour that is leading to relationship problems. Another issue that arises is the reason for the particular human or organizational behaviour.

The following is a quote that depicts another dynamic of the buyer-supplier relationship. This process is the gaming approach and is relevant to the issue of what exactly happens between buyers and suppliers during a transaction.

'It really doesn't matter if an OEM [original equipment manufacturer] needs cost cuts immediately, he asserts. Because the arbitrary approach is a gaming approach and suppliers will learn to play faster than the OEM. There are more suppliers to gang up on automakers and the program will become adversarial. Then everybody loses.' [3].

\section{SUPPLY CHAIN ALIGNMENT}

The alignment of the structure and operations of supply chains (demand networks) has been the focus of a number of recent papers in the area of supply chain management [4-6]. Various publications have been devoted to addressing questions regarding alignment of supply chains and the issues involved in aligning. This research has been conducted under the auspices of a project 'The development of a systemic framework for supply chain alignment' funded by the Engineering and Physical Sciences Research Council. The project was initiated with the intention of studying the various variables, which would provide an insight into the question: how can the right supply chain be selected and what can it be aligned to? There has been research conducted on numerous occasions on the aspect of selecting the right supply chains. However, previous research has primarily focused upon operational supply chain alignment and most notably the alternative lean and agile models. According to the existing classification and models, supply networks must design their business strategy according to, first, market requirements and characteristics and, second, the rate of new product introduction. These two factors can be determined by product type $[4,7]$, product complexity (if applicable) [6], and process [7]. In terms of operations, the strategy, according to Naylor et al. [8] and Christopher and Towill [9], can be engineered to design the production systems to be lean or agile or perhaps both (the concept of leagility) to take simultaneous advantage of the ben- efits of leanness and agility. In practice, this means that product configuration should be postponed along the supply chain according to the market characteristics.

This view of alignment depicts the alignment of the demand networks to the market requirements. The presence of humans in the supply chains warrants further study for considering human behaviour as an important aspect of alignment. This has been proposed to some extent by Gattorna and Walters [10]. According to them, the four key elements that make up the strategic alignment model are as follows:

(a) the market and/or client base;

(b) the organization's strategy with which it responds to the market;

(c) the organization's culture, which represents its internal capability to implement this strategy;

(d) the leadership and/or management style that it uses to shape the culture and to drive the strategy.

Any strategy is only appropriate in a given set of competitive conditions. Also, specific organizational cultures and leadership styles are only appropriate for given strategic situations. Alignment is the 'appropriateness' of the various elements relative to one another [10].

Although the role and impact of information transparency along the supply chain have been reasonably emphasized and elaborated in this stream of studies, there has been relatively little work to align the strategic and operational perspectives with the information system viewpoint $[\mathbf{1 1}]$. A second stream [12] has focused on relationships in supply chains and in particular has suggested the power regimes (dyadic relationships between players in a supply chain) and power distribution in the supply chain as the responsible factors for the structural form and operation, and hence the alignment of the supply chains. This approach mainly focuses on value appropriation as the main objective in the creation and management of a supply chain, which corresponds to the power attributes of the supply chain. Both approaches have endeavoured to develop theories for supply chain management and to discover the 'DNA' of business and supply chains [13].

Another approach that has been followed by researchers in studying and aligning supply chains is the focus on performance measures. It has been realized in recent years by a number of firms that they often lack the insight for the development of effective performance measures and metrics needed to achieve a fully integrated supply chain. Moreover, such measures and metrics are needed to test and reveal the viability of strategies without which a clear 
direction for improvement and realization of goals would be highly difficult [14]. According to Hausman [15], supply chains need to perform on three key dimensions.

1. Service. Service relates to the ability to anticipate, capture, and fulfil customer demand with personalized products and on-time delivery.

2. Assets. Assets involve anything with commercial value, primarily inventory, and cash.

3. Speed. Speed includes metrics, which are time related; they track responsiveness and velocity of execution.

Hausman proposed that every supply chain should have at least one performance measure on each of these three critical dimensions. Tracey et al. [16] reported that the quality of a firm's supply chain management processes moderate its ability to please clients. Their research provides strong support for Day's [17] contention that companies must sustain certain types of capability regardless of industry in order to remain competitive.

Lee et al. [18] pointed out that 'unlike the past, the performance of an enterprise now depends much on the performance of its partners in the value chain'. Despite the variety of existing frameworks for performance measurement, most organizations are still unable or unwilling to measure and manage performance collaboratively with partners [19]. Collaborative performance measurement and management means that customers and suppliers obtain access to and give access to performance information beyond their own firm to the other partners in the network. By sharing performance data with partners, firms can identify the 'weak links' in the network and act in accordance to improve the overall performance $[\mathbf{2 0}, \mathbf{2 1}$ ]. The difficulty of developing a collaborative culture and the difficulty of developing appropriate performance measures have been identified as the major barriers to the successful implementation of collaborative performance management systems [22]. Macbryde and Mendibil [23] suggested employing three different kinds of measure based on team performance management.

1. Process measures. Is the process performing?

2. Teaming measures. Are people working in teams?

3. Team management measures. Is management providing an environment conducive to team working?

In contrast, Lambert and Pohlen [24] suggested framework to align performances of each customer-supplier link through the mapping of the supply chain, with analysis of each link by identifying and evaluating financial implications.

The work on performance measurement systems focuses on the need for supply chains to compete against other supply chains through the alignment of supply chain practices with strategy, utilizing a performance measurement system. However, it is important to consider that the metrics must be tailored to the value proposition of the supply chain, hence bringing an alignment between supply chain and business strategy. A supply chain whose value proposition is low cost should not emphasize flexibility and responsiveness metrics [4, 15], since they could detract from that chain's fundamental competitive strategy. Similarly, a supply chain whose value proposition is innovative technology should not emphasize cost factors, since they could detract from that chain's strategy [15]. It is thus critical that the specific metrics chosen should align with the chain's business, product strategy, and value proposition.

\section{RESEARCH APPROACH}

The literature review on supply chain relationship issues highlighted the relevance of various factors in influencing supply chain relationships. These factors are as follows: power, opportunistic behaviour, unethical behaviour, exit-voice, and trust. To obtain a better insight into the factors affecting supply chain relationships, the research approach used was that of qualitative research. The methods used were that of phenomenological interviewing with focus on critical incidents [25]. The critical incident technique is a method for coming close to direct observation but avoiding some of its hardships [26]. According to Bitner et al. [27], the critical incidents technique generates data with the level of detail and richness that puts the researcher close to the realities of the process being studied; it is almost direct observation. It is an inductive method in which no hypotheses are needed and the incidents as they appear are allowed to form patterns that the researcher can develop into concepts and theories [26]. Critical incidents can be a source of criterion sampling [28]. Boyd [29] regarded two to ten participants or research subjects as sufficient to reach saturation (discussed in reference [30]), and Creswell [31] recommended 'long interviews with up to 10 people' for a phenomenological study. The sample size for this research was 12. Although the sample size has support from the previously mentioned references, a major reason for having such a small sample was the availability of respondents and the time constraints of this research to interview more respondents. Also, as stated above, the critical incidents served as the sample, hence all the critical incidents derived from the 12 interviews served as the data sample. The respondents selected for the first-stage interviews were automotive 
dealers, food-manufacturing firms, engineering firms, and distributors. The total numbers of respondents were 12 firms of which three firms were from India. Of the three Indian firms, two firms were engineering firms, and one was a distributor for a 'fast-moving consumer goods' manufacturer.

Another data set for the research was data derived from literature. This data set consisted of research publications [2], journal papers [32], newspaper reports $[\mathbf{3 3}, \mathbf{3 4}]$, articles from business magazines $[\mathbf{3}, \mathbf{3 5}, \mathbf{3 6}]$, information reported on websites $[\mathbf{1}$, 37], and competition-commissions reports [38]. The data from these literature sources were analysed similarly to the data from interviews. Using data from both individual interviews and literature provided a richer picture of the transactions and buyer-supplier relationships. Since the interviews could not be recorded and transcribed owing to the sensitive nature of the information, for analysis purposes the data were taken from notes written on the 'contact summary sheets' and 'document summary sheets'. The analysis was carried out as suggested by Miles and Huberman [39] using the early analysis techniques and in the same sequence as the interviews were conducted. Another reason for not having a strict regime for data collection and analysis was that, since the research focus was exploring relationship issues from the human perspective, the researcher was not taking any particular stand from either the buyer's or the supplier's viewpoint and hence the randomness of the data in terms of mixing views from both buyers and suppliers was not a cause for concern. Relevant units of meaning were extracted from each interview. These units were in the form of quotes, words, and critical incidents (as a complete unit). These units were clustered into themes, which were referenced from the literature review. Any cluster, which did not represent known themes, was given a new name. The data in the field notes were analysed for these themes. The interview data were studied and, where any information pertained to a specific theme, it was recorded in parentheses near it in the field notes. The information depicted in the field notes was classified using the codes derived from the concepts studied in the earlier section. The major concepts, which were formed in to themes were as follows: power, exit-voice, unethical behaviour, trust, situational strength, and opportunistic behaviour. The contact summary sheets had codes (themes) inserted from the initial analysis of the field notes. Further analysis of the information on the contact summary sheet broke down the information into new themes, which had not been studied by the researcher in the literature search. The data, which were derived from the literature, were analysed using the same method. The same themes or codes, which were used to analyse interview data, were used for analysis of literature data. This information was then transferred to the document summary forms. The document summary forms were analysed and new themes emerged. These themes were then compared with those obtained from the interview data and the research focus was narrowed down for this research. The analysis introduced two more factors:

(a) game-like behaviour;

(b) discretion that humans have in the relationship.

These two factors were studied using the concepts of transactional analysis and situational strength $[40,41]$.

\section{THE RELATIONSHIP ALIGNMENT METHODOLOGY}

The research presented in this paper focuses on the alignment issue from the perspective of relationships across the supply chain. It implies that a necessary requirement for supply chain alignment is the consideration of the perceptions that a buyer and a supplier have about each other's performances and their perceptions when entering into the relationship. If the perceptions align and the transactions complement the perceptions, then the relationship works seamlessly and the supply chain is aligned. The transactions when complementing the perceptions can take the form of operational, financial, or purely behavioural elements. In this research the methodology suggested takes into account the alignment of the perceptions with the behavioural elements of the transaction. The behavioural elements could also be the manifestation of operational or financial issues. The core analysis in this research is to consider the behaviour that has occurred in the transaction or the psychological underpinnings owing to the transaction conducted by the entities.

To use the methodology (Fig. 1), the user first identifies the transaction that he or she needs to evaluate. The user then collects all relevant data related to the transaction so that he or she has a detailed idea of what happened in the transaction and what was the result. The user then compares the result with the perceptions and expectations that he or she has with the relationship. For this analysis the concept map and the relationship matrix are beneficial, as the concept map presents to the user the different factors that are affecting the perceptions and expectations, and the relationship matrix provides further insight into the relationship based on the levels of satisfaction and the strategic movements that occur owing to a certain level of satisfaction. This aspect of comparing the result of the transaction with the inherent expectations in 


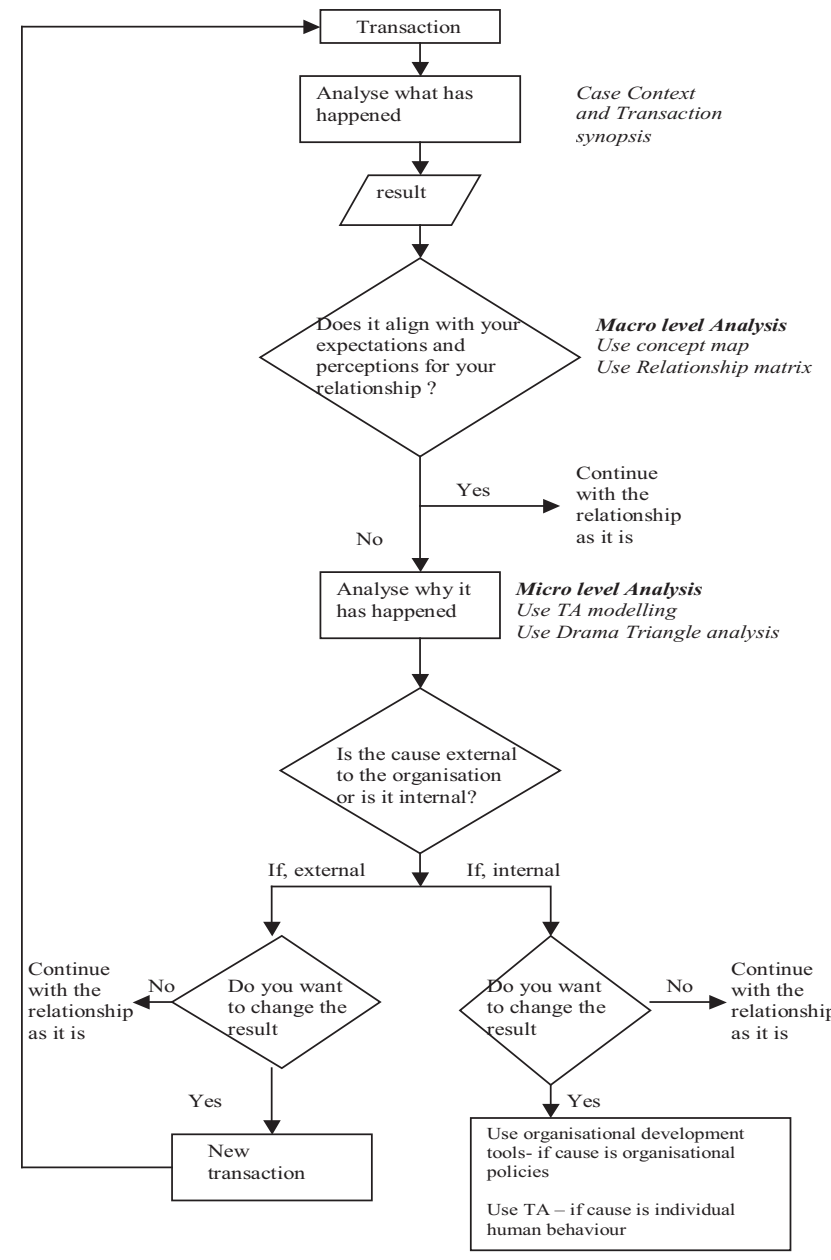

Fig. 1 Methodology for studying buyer-supplier relationships (TA, transactional analysis)

the relationship (macro-level analysis) is an important step as it highlights the aspect of alignment and the importance that alignment plays in the strategy of maintaining relationships. If the result and the expectations align, then the user decides to continue with the relationship as it is. If there is no alignment between the expectations and the result, then the user analyses the transaction for the causes of the discrepancy. For this analysis (micro-level analysis), the user uses the techniques of transactional analysis modelling and drama triangle analysis, which will help to depict the dynamics of the transaction. This analysis will also provide insight into whether the cause of the transaction and the subsequent result were due to an external source or an internal source. If the cause has been identified as internal, then it could be either at an organizational level or at an individual employee level (situational strength). The decision at this stage would be whether to try to change the result. If the answer is no, then the user would continue with the relationship as it is. If the answer is yes, then the solution would depend upon whether it is at an organizational level or at an individual level. If the cause has been identified as an external source, then there is again the decision whether to try to change the result. If the answer is no, then the user would continue in the relationship as it is. If the answer is yes, then the user would conduct a new transaction in order to obtain a result that would align with his or her expectations from the relationship.

\section{ELEMENTS OF THE METHODOLOGY}

The methodology is a process map of a series of steps to be conducted for a supply chain entity to assess its relationship. It consists of a number of tools to be used at various stages of the analysis. The development of these tools and their use have been reported in previous publications. Hence, in this paper these tools will not be detailed but only referred to. The different elements of the methodology are as follows.

\subsection{The concept map (see Fig. 2 later)}

To obtain a comprehensive understanding of the different concepts studied within the context of this research, the present authors have used the technique of developing a 'concept map' or 'conceptual framework' as described by Miles and Huberman [39]. According to them, a conceptual framework explains either graphically or in narrative form, the main things to be studied (the key factors, constructs, or variables) and the presumed relationships between them. Frameworks can be rudimentary or elaborate, theory driven or commonsense, and descriptive or causal. The concept map is a compilation of the thinking and research in references [12], [13], and [42-46] and aims to determine whether regular patterns of communication take place between collaborating and transacting companies. The concept map is very important in terms of this research as it brings together different concepts into a structure that provides an important insight into the processes occurring in the relationship. The transactions or game-like behaviour depicted is the culmination of the relationship process, which further affects how the relationship will be conducted in the future.

The thinking behind developing the concept map is as follows. When conducting the literature review the aspects of market and demand pressures on supply chain management were studied in depth and this led the present authors to focus on the aspects of the pressures on the transacting entities to conform to perceptions of performance [47] and level of interest that each entity has in the other. These factors play an important role in deciding who has 
power in the relationship and this is supported in the literature by references [12], [42], and [48] when discussing power structures in supply chains and the four different power regimes, namely buyer dominance, supplier dominance, independence, and interdependence. The analytical framework developed by Cox et al. [48] recognized that, although power advantages might often not be explicitly exploited in buyer-supplier interactions, the very existence of a power imbalance affects buyer and supplier behaviour. They contend that power does not become any less important to an understanding of buyer-supplier relationships simply because it is not exercised. Whenever companies or individuals interact, there is bound to be some relationship pattern. Sometimes, this may be dysfunctional and need some action to improve it. At other times, it may lead to highly productive relationships. The extent to which the relationships can be planned and controlled is difficult to define.

The power structures seems to suggest that in terms of dominance and independence the dominant entity may or may not amicably find solutions when issues arise in the relationship, but in situations of interdependence the entities in the relationship always strive to find solutions to any issues in order to keep the relationship working. The aspect that entities try to make or break the relationship has support from the research conducted by Helper [44] using the concepts of exit and voice proposed by Hirschman [43].

The present authors have previously proposed [49] that the communication patterns for conducting the supply chain relationship will vary as per three situations: day to day, stress, or negotiation. Hence the power structures and the use of exit or voice will have a profound effect on how communication is conducted during any of three situations.

Once the communication pattern is known, it is also important to know who will be conducting the transaction and at what level. The concept of situational strength [45] gives further insight into this issue of whether the individual conducts the transaction on his or her own or conducts it as per the guidelines set out by the organization that he or she is representing. In this case, if the situation is strong, then the individual conducts the transaction as the organization wants it to be done whereas, if the situation is weak, then the individual is free to exercise his or her own discretion in the conduct of the transaction. The exact form of the transactions depends upon the strength of the situation and the learnt patterns of behaviour, which have been developed either within the organization (strong situation) or by an individual who has autonomy to decide on interaction communication (weak situation). In addition to the comparative power between collaborators the commitment to resolving any problems is also important. In this research the concept of the voice and exit strategies is used. Voice participants are generally members of an inner group that argue out and negotiate problem situations while exit strategy participants generally exit the relationship when serious problems emerge. A buyer often uses an exit strategy when there is a wide range of supply alternatives and he or she is not committed to purchasing from a particular supplier. The derived concept map incorporates power difference, voice, and exit strategy in addition to the concept of situation strength. A weak situation is one where there is some ambiguity and latitude in defining the rules of the relationship and, consequently, interacting people have significant discretion in deciding the transaction patterns. This is in contrast with a strong situation where the discretion for the individual in decision making is less and the transaction pattern is strongly influenced by the rules of the group or organization. The transactions may vary across each value stream inside a company or there may be a consistent policy for all the value streams. A pervasive power culture, a large defensive company, and a highly regulated company will probably have set procedures for handling negotiation, and this will result in a strong situation as defined by Mischel [45] where company policy dictates the transaction process. Some companies may maintain relatively low levels of trust within their respective organizations and, as a consequence, higher levels of regulation [50]. Such firms are also likely to impose high levels of regulation upon their lessdominant partners.

The final aspect of the concept map stresses the use of transactional analysis and the concept of games as set out in transactional analysis [51]. The concept map suggests that the transaction may be conducted as a game by the entities in order to obtain the required pay-off. If the situation is strong, then the pay-off is decided by the organization and the evident game-like behaviour during the transaction is also decided by the organization. If the situation is weak, then the individual decides his or her individual pay-off together with the required organizational pay-off and depicts game-like behaviour as reported in the literature on transactional analysis games. Using the terminology of transactional analysis $[\mathbf{5 1}, \mathbf{5 2}]$, the concept map identifies the situations, which can produce such patterns. The patterns form the basis of what are called organizational games, drawing parallels with the individual games described by Berne [51]. An organizational game is a regular pattern of ulterior transactions between organizations, generally resulting in a negative pay-off for one of the partners. An ulterior transaction is a communication pattern containing 
psychological messages, which may not be consistent with the spoken communication. It is the assumption that the actual variety of these complex repeating patterns of games can be modelled using transactional analysis game theory. One of the beliefs arising from the concept map is that for the weak situation the game set is largely specified and controlled by individual personality, while for the strong situation the interaction between the person and the organization is more complex and the organization controls to a greater extent the transaction patterns between collaborators. These game-like behaviours in the strong situation can be called organization games. The organization game set is likely to be still part of the repertoire of games defined by Berne [51] but they form a unique set that is strongly influenced by the organization rules and procedures about behaviour preferences.

Although the concept map depicts that the concepts have a direct relation between them in the transaction process, this has not been proved and is shown through intuitive reasoning based on the literature review of the concepts studied. It was not in the scope of this research to prove the effect of each concept on the other, but more to study the effect of power, exit-voice, and situational strength on the game-like behaviour shown during transactions.

\subsection{The relationship matrix (see Fig. 3 later)}

Once a transaction is conducted between the supply chain entities, it is assumed that each entity queries the event in the following way (this is an assumption and is not in any way proof of what entities actually do, but it is logical to consider the following questions).

1. Did the transaction proceed as required?

2. Was the pay-off (outcome) received as required?

3. Is it required to change the pay-off or the way that the transaction is conducted?

The present authors suggest that depending upon the outcome of the transaction there would be four states of satisfaction.

1. The buyer is satisfied; the supplier is dissatisfied.

2. The supplier is satisfied; the buyer is dissatisfied.

3. The buyer and supplier are both dissatisfied

4. The buyer and supplier are both satisfied.

The states of satisfaction and the psychological underpinnings of the relationship are thus explained through the formulation of the relationship matrix, which represents the relationship scenarios in four quadrants. Even though the relationship scenarios look similar to the framework developed by Cox et al. [12], it does not in any way undermine the importance of the original framework and supports it by adding another dimension to the study of buyer-supplier relationships. For a detailed explanation of the matrix and the change in the relationship based on the quadrants, see references [53] and [54].

\subsection{Transactional analysis modelling (see Fig. 4 later)}

For an explanation of transactional analysis $[\mathbf{5 1}, \mathbf{5 2}]$ and the use in this research, see references [40] and [55]. This stage studies the transaction from the perspective of transactional analysis to gauge how the humans involved are conducting these transactions and the psychological underpinnings of their actions when subjected to strong or weak situations. This stage depicts the dynamics of the transactions using the structural modelling capabilities of transactional analysis.

\subsection{Drama triangle analysis (see Fig. 5 later)}

This step of the analysis comes into existence only when the transactions depict game-like behaviour, which alters the power status of the entities after the transaction is conducted. This behaviour can also be studied using the drama triangle analysis technique used in transactional analysis. The drama triangle analysis technique provides a psychological perspective to the transaction. It is eligible only for transactions or behaviours, which have the capacity to be termed game-like behaviours. For regular transactions, even though there may be crossed transactions, it is not necessary that a switch would have occurred in the roles being played by the two entities in the relationship. Hence, in the case of a buyer and a supplier it is interesting to note the roles that the two entities are in before the transaction or behaviour is conducted, and the roles that they are in after the event. The switch of roles and the behaviour shown by the entities provides greater insight into the type of relationship that the two entities have with each other, and what to expect in the future. For example a buyer may have a tendency to start the transaction in the rescuer mode, by offering various incentives to the supplier to start supply, and eventually, as the supplier is locked in, the buyer switches mode to that of persecutor and changes requirements of the contract or adds some more conditions, which the supplier has to follow. By using the drama triangle analysis, the supplier can assume that it is the tendency of a certain buyer to move into the persecutor mode later in the relationships; hence, the supplier can make a 
decision either, first, not to enter into a relationship with the buyer or, second, to change behaviour in order to gauge the moment of switch and pull the switch itself to obtain the upper hand in the relationship. In another example, the buyer, who initially has the power, is in the persecutor mode and controls the relationship, while the supplier is in the victim mode. When the transaction completes, the supplier then possesses power over the buyer and hence the supplier switches to persecutor mode; thus the supplier starts to control the relationship and the buyer moves to the victim mode. As described above, if the transaction brings about this switch, then the dynamics of the transactions are studied using the method of drama triangle analysis $[\mathbf{5 1}, \mathbf{5 2}]$.

\section{USING THE METHODOLOGY}

\subsection{Case study: 'Got you'}

\subsubsection{Case context}

The respondent in this case was the owner of the company. The company is a small and medium enterprise (SME) supplying crankshafts to a very large automobile-manufacturing company. The researcher contacted the owner for an interview, which was held in the premises of the company at $6.00 \mathrm{pm}$ after office hours. The names of the persons involved in the interview and the organizations cannot be displayed here owing to the sensitive nature of the information. The researcher explained to the respondent that he was studying buyer-supplier relationships and asked the respondent to describe his relationship as a supplier to the large automobile company. The respondent explained how the relationship was formed and the various investments made by the supplier company to build the complete operations of the company around the requirements of the buyer company. The researcher then asked the respondent about any issues or problems encountered by the supplier in this relationship. The respondent explained that, in the past, small issues were always sorted out on a personal basis between the respondent and the purchasing representatives of the buyer company. He also said that payment was a constant issue as the buyer company never paid on time. The researcher then asked the respondent to comment on the future of the relationship, wherein the respondent, although not ready to divulge any more information, relented and explained to the researcher how the buyer company was changing its supply strategy, which was going to affect the supplier company to a great extent and how the supplier company was thinking of dealing with the new development in the buyer-supplier relationship. This new development in the relationship has been analysed by the researcher below using the frameworks and transactional analysis.

\subsubsection{Transaction synopsis}

The supplier has invested in resources for the last four years and made a business surrounding the supply. The buyer is very powerful and so dictates, contracts only once, decides price, and does not negotiate or recontract later; the supplier has to abide by the buyer's rules. Recently the buyer has decided to create a new supplier network with only two companies as first-tier suppliers, and then it will streamline the previous supplier network by delisting many suppliers abruptly without notice and then force the remaining to act as second-tier suppliers, potentially reducing supplier margins. The buyer has a commercial stake in both the firsttier companies.

Analysing this information using the concept map (Fig. 2) provides information about the dynamics of the transaction. The buyer in this case is powerful and the power structure is in the buyer-dominated mode. The buyer uses an exit strategy, wherein it asks the supplier to follow the terms of the buyer or else to quit. The relationship at the moment of the transaction is in stress-and-negotiation mode. The buyer is a large company and has a strong situational strength, hence the actions of the purchasing representatives of the buyer are controlled by the policies set by the top management, and in this case the buyer is trying for a change in the supply chain structure; hence, if the organization uses the gaming approach, the transactions are more influenced by organizational and cultural issues rather than by individual discretion.

\subsubsection{Supplier action}

The supplier knows that the buyer is powerful and that the supply contract will be lost within a year's time; so, owing to the pressure and fear of loss, the supplier has decided to attempt to increase its own personal power. The supplier has developed the ability to gain a power position. The supplier made parts supply indispensable and then checked whether any competitors could deliver. Once it was known that there was no competition, the supplier ramped up the price by 40 per cent, which the buyer had to comply with for a short term, as it did not want to stop the supply. The supplier meanwhile is looking out for other buyers and trying to integrate horizontally. The buyer will have to comply with the supplier process for a few months until a new supply source can be developed. 


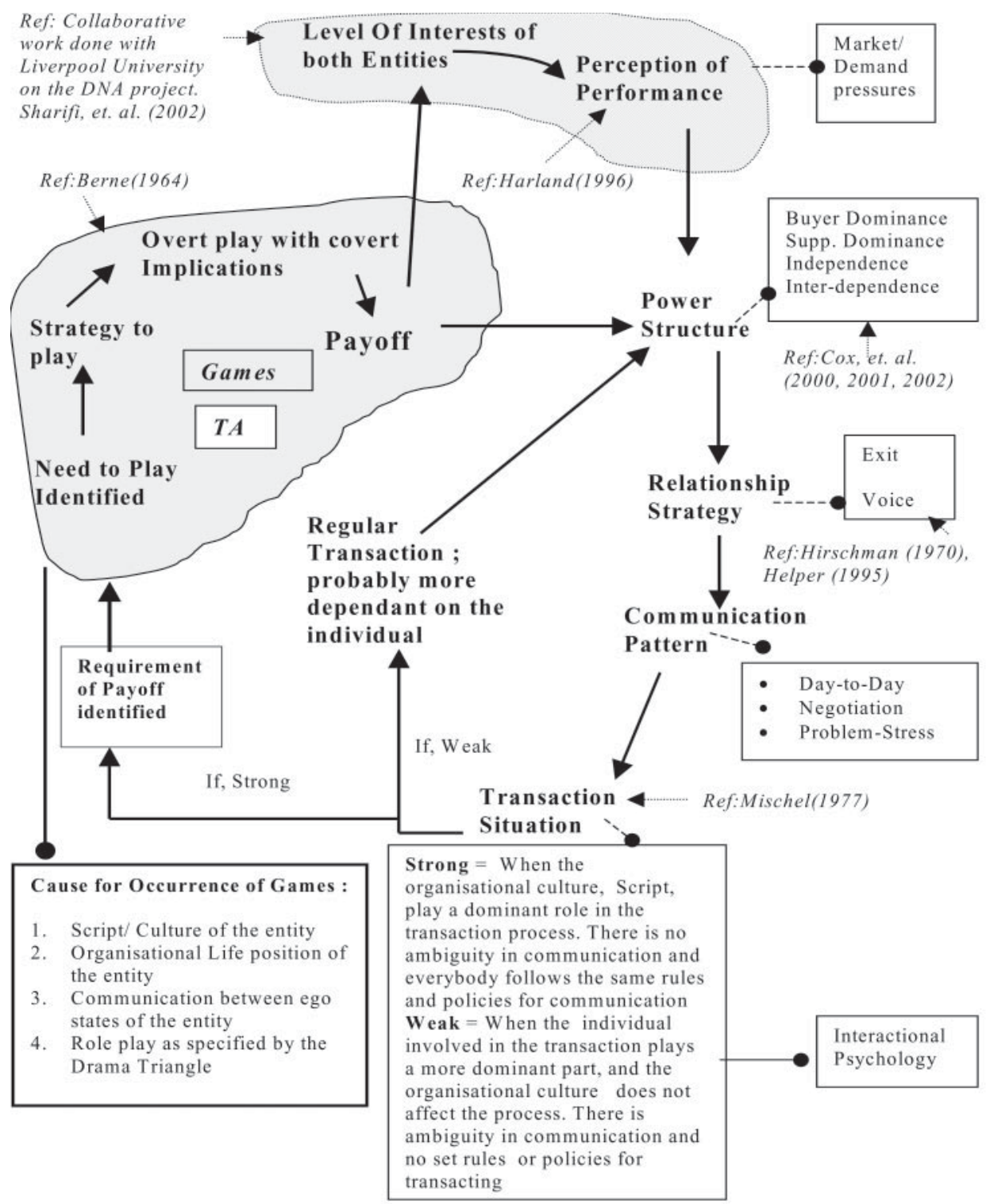

Fig. 2 The concept map [40]

\subsubsection{Analysis}

Studying the information available for this case and using the relationship matrix (Fig. 3), it is possible to ascertain that, for some time, the relationship was in quadrant I, as the buyer was satisfied with the relationship and the supplier, even though dissatisfied, had agreed to the status quo. For a long time the relationship continued in quadrant I even though there were moments when the supplier would have voiced disagreement to the buyer but eventually did not try to change the status of the relationship for fear of losing the business. The buyer decided to move the relationship to quadrant II, when it asked the supplier to modify its position in the supply chain from a first tier to second tier, thus reducing the supplier's margin. If the supplier did not comply, it would be delisted and the buyer and supplier would exit from the relationship. The supplier eventually knew that in a few months' time it would have to exit as continuing the relationship was not financially feasible; so the supplier decided to change strategy for the last few months. As stated earlier, the supplier collected information about the buyer's other sources of supply for the product that it was supplying. On finding that it was difficult for the buyer to find a source of supply soon, the supplier decided to take the relationship to quadrant III by increasing the price of the product by 40 per cent as it knew that the buyer had no other alternative. Thus for a few months the supplier was able to move the relationship to quadrant III but knew that eventually it is going to move to quadrant II, when the buyer finds an 


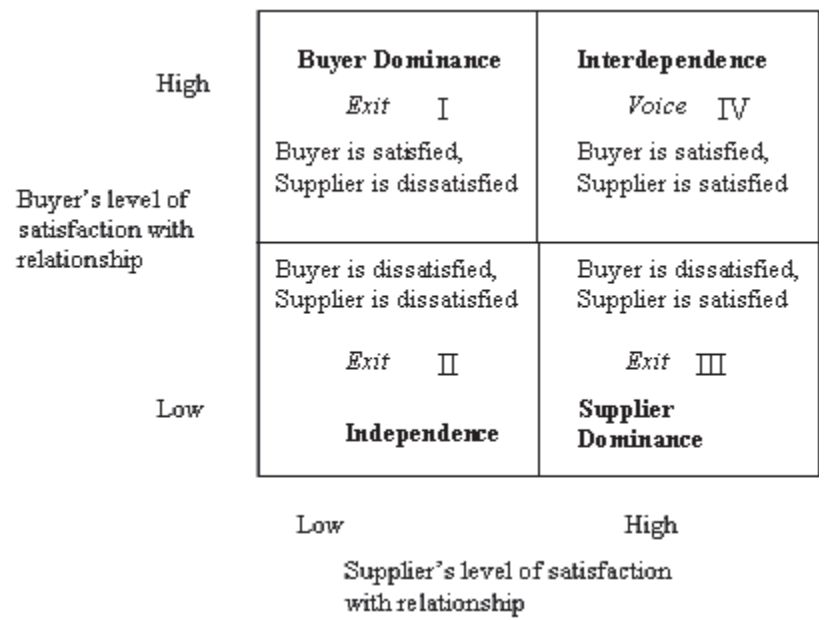

Fig. 3 The relationship matrix [54]

alternative source of supply and then ends in an exit relationship.

This analysis sounds rather simplistic but, if the reader would delve into the underlying processes in this transaction, there are elements of a power struggle, the use of resources to achieve maximum advantage, the use of porter's strategy, and finally decisions based on exit-voice strategy which determines the health of the relationship. Also, as stated earlier, it is not the objective of the researcher to present the best relationship situation or critique on the disadvantages of certain relationship situations as in the work by Carter [2]. In this case, two game-like behaviours are shown.

1. The first behaviour is shown by the buyer firm, when it decides the strategy to make more money by changing the supply chain structure. Even though this may seem to have no direct psychological implications and look like a very rational strategic move, it can still be modelled using transactional analysis. The psychological transactions are more of the covert transactions shown by the buyer in depicting its power position to the supplier.

2. The second game-like behaviour is shown by the supplier firm, when it sees that the buyer has no alternative to procuring the product and increases the price to obtain an advantage for a short duration. This again may look like a very rational transaction, but this has the underpinnings of a psychological transaction. The two game-like behaviours are actually parts of the complete transaction that starts with the buyer transacting from the parent mode, the supplier reacting from the parent mode, thus making it a crossed transaction, and then the buyer again obtaining control of the situation and ending it in the parent mode. This type of game-like behaviour has been noticed in various literature cases reviewed and interviews conducted by the researcher.

Thus quadrant I $>>>>$ quadrant II $>>>>$ quadrant III $>>>>>$ quadrant II

\subsubsection{Transactional analysis modelling (Fig. 4)}

1. Being a powerful entity, the buyer is in a position to control the relationship. Hence, the buyer has decided to streamline its supply base for strategic gains, but at a level of discomfort for the suppliers. The buyer then asks the supplier in the case to change status from first-tier supplier to second-tier supplier. This is an adult-to-adult transaction and is represented by transaction 1 , but it does send out an ulterior message, represented by transaction 2 , which says that the buyer is powerful and that it is essential for the supplier to concur (Fig. 4).

2. The supplier does not accept this but does not communicate about this to the buyer. The supplier wants to take revenge on the buyer and hence searches for a way to get even. The supplier recognizes that the buyer is dependent on the supplier for the parts being supplied. The supplier wants to exit from the relationship but, before doing that, wants to retaliate. Hence, the supplier ramps up the price of the parts by 40 per cent and threatens to quit. This transaction occurs at an adult-to-adult level, represented by transaction 3 . The ulterior transaction is represented by transaction 4 , where the supplier has the power and represents 'got you'.

3. The buyer knows that at least for a short time, until an alternative supply base can be created

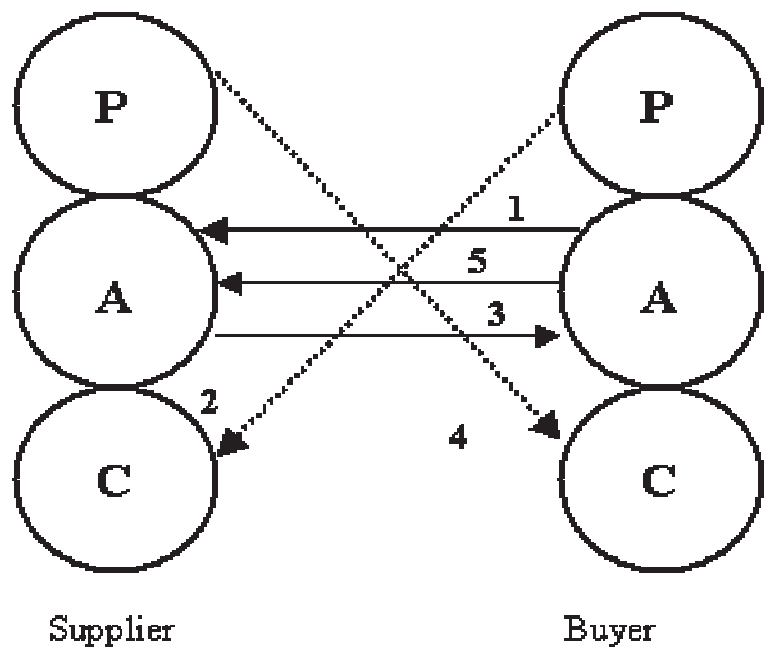

Fig. 4 Transactional analysis modelling ( $\mathrm{P}$, parent; A, adult; C, child) 

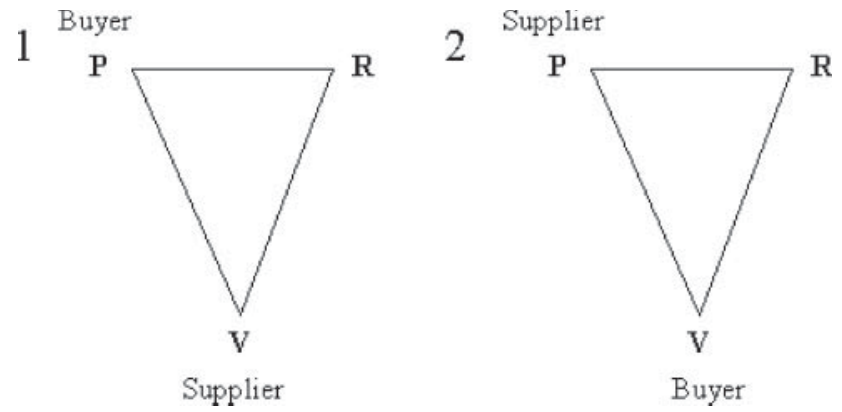

Fig. 5 Drama triangle analysis (P, persecutor; $\mathrm{R}$, rescuer; $\mathrm{V}$, victim)

for the parts, it is necessary to comply and hence to accept the price increase, which is again an adult-to-adult transaction and is represented by transaction 5 .

The behaviour depicted by the supplier in this case has been noticed in various forms in cases where suppliers use the lock-in strategy or increase the prices after the contracts have been signed and the buyer becomes dependent upon the supplier for supply.

\subsubsection{Drama triangle analysis (Fig. 5)}

In this transaction, the buyer starts the transaction in persecutor mode, wherein the buyer exerts power, and the supplier takes the role of the victim, is less powerful, and has to abide by the buyer's requirements. However, as the transaction proceeds, the switch occurs when the supplier ramps up the price. The supplier knows that the buyer is completely dependent on the supplier for the parts; hence the supplier switches from the role of victim to that of persecutor. The buyer now occupies the role of victim and has to comply with the supplier's requirements until the buyer can create another switch to reverse roles.

\section{DISCUSSION}

The case study has shown that the methodology can provide a rich information base for the transactions between buyers and suppliers. The advantage of using the methodology is that it analyses the same information through different perspectives using various tools developed during this research project. One of the most important aspects of the methodology is the focus on human behaviour in the relationships and transactions and providing the user with an insight into the various issues surrounding supply chain relationships on account of human behaviour. Another important aspect of the methodology is the inclusion of transactional analysis, a tool used in therapeutic counselling to analyse the supply chain relationships. Transactional analysis provides a very valuable tool for displaying the information transfer between partners in the supply chain. It can represent the ulterior messages at the same time as the psychological message and hence provide a rich picture about the transactions. In this research the concept of games has been used. The games, as developed in transactional analysis, are repeating patterns of transactions that occur between supply chain partners. Transactional analysis was applied to organizations by Berne himself with the concepts of character, etiquette, and technical culture matching the child, parent, and adult states respectively. However, games in transactional analysis are generally carried out at an unconscious level and relate to learnt patterns of behaviour and to re-enforce beliefs about the self. Between organizations the games are often more conscious and planned actions correspond to unspoken transaction strategies. The information modelling capability of transactional analysis provides a rich picture about what is being verbally and non-verbally communicated. It is also possible to identify transactions inside the organization that match the parental judgements, the logical adult, and the emotional child.

An important question is: once game-like behaviour is identified, what can be done about these rather negative game-like patterns? It is not even obvious that any company would actually choose to be open and frank and to eliminate these games, particularly if they gain some strategic advantage and power from them. All the parties in the transactions have to see these games as being negative before any concerted action can take place to eliminate the game-like behaviour; only then would the therapeutic methods of transactional analysis be appropriate. Being aware of the game and having a deliberate strategy to interrupt the pattern of transactions once identified would end the games. Also using governance mechanisms similar to those defined by Jap [56] to control the incidence of opportunistic behaviour could significantly reduce the likelihood of games. This information has been represented in the decision support structure of the methodology and the users can then decide to what level they would use the methodology. Also, the use of the methodology would be an ongoing process as transactions would be conducted on a continuous basis between the entities, until both the entities 
agree to the situation of satisfaction and power and conduct the relationships at the agreed level or if one of the entities decides to quit.

\section{CONCLUSIONS}

The case discussed above has been analysed retrospectively using the methodology. It has been successful in depicting and analysing the transaction that has occurred between the buyer and supplier. The methodology is a process map, which takes the user through a series of decision steps in order to analyse the actions that the user needs to take. The methodology does not provide solutions for gaming or ulterior transactions, but it does provide a method for analysing the transactions for any gaming approaches. Also, if the cause for the ulterior transaction is an internal cause, then the solution for rectification as shown by the methodology is the use of organizational development tools or transactional analysis. It might be wondered whether this can be used only as a reactive tool to analyse situations that have already occurred, or whether it can be used in a proactive way to chart out a new strategy. The methodology is useful if used as a tool for recommending a change in strategy or for pointing in the right direction for information in order to change the relationship strategy. The recommendations or suggestions provided for moving to quadrant IV (partnerships) is more related to using existing research published regarding partnership theories and collaborative practices. Also, as the supply chain relationship research domain increases with new research published, this methodology will remain a basic tool, and the new research can be inculcated as a recommendation for strategy change. The above case provides the reader some insight into the dynamics of the relationship.

One of the limitations of this research until now has been, as stated earlier, the use of this methodology for analysing ongoing transactions and taking decisions to align relationships. The use of this tool for aligning and assessing relationship transactions is an ongoing research process. The research so far has been able to use a sample of 12 firms for retrospectively validating this methodology owing to the sensitive nature of the information that is deals with. Whatever data have been available, however, have been beneficial in the development of this methodology and, as this methodology gains recognition, there will be more opportunities to utilize the tool for analysing ongoing transactions and thus to align supply chain relationships.

\section{ACKNOWLEDGEMENT}

The authors would like gratefully to acknowledge the support that the Engineering and Physical Sciences Research Council, UK, has extended towards them for this work.

\section{REFERENCES}

1 Anon. Are supermarkets really to blame? http://www. readymealsinfo.com/articles/supermarket.htm-(accessed 3 July 2003).

2 Carter, C. R. Ethical issues in global buyer-supplier relationships, 1998 (CAPS Research-National Association of Purchasing Management, Tempe, Arizona).

3 Kobe, G. Supplier squeeze. Automot. Industries, March 2001. http://www.ai-online.com

4 Fisher, M. L. What is the right supply chain for your product? Harvard Business Rev., March-April 1997, 105-116.

5 Harland, C., Lamming, R. C., and Cousins, D. Developing the concept of supply strategy. Int. J. Ops Prod. Mgmt, 1999 19(7), 650-673.

6 Lamming, R., Johnson J., Zheng, J., and Harland, C. An initial classification of supply networks. Int. J. Ops Prod. Mgmt, 2000, 20(11), 675-691.

7 Fine, C. H. Clockspeed: winning industry control in the age of temporary advantage, 1998 (Little, Brown and Company, London).

8 Naylor J. B., Naim M. M., and Berry D. Leagility: integrating the lean and agile manufacturing paradigms in the total supply chain. Int. J. Prod. Econ., 1999, 62, 107-118.

9 Christopher, M. and Towill, D. Supply chain migration from lean to agile and customized. Supply Chain Mgmt: Int. J., 2000 5(4), 206-213.

10 Gattorna, J. L. and Walters, D. W. Managing the supply chain: a strategic perspective, 1996 (Macmillan, Basingstoke, Hampshire).

11 Lamming, R. C., Cousins, P. D., and Notman, D. M. Beyond vendor assessment: the relationship assessment project. Eur. J. Purchasing Supply Mgmt, 1996, 2(4), 173-181.

12 Cox A., Sanderson, J., and Watson, G. Power regimes mapping the DNA of business and supply chain relationships, 2000 (Earlsgate Press, Strafford-uponAven, Worwickshire).

13 Cox, A. Power, value and supply chain management, Supply Chain Mgmt: Intl. J., 1999, 4(4), 167-175.

14 Gunasekaran, A., Patel, C., and Tirtiroglu, E. Performance measurement and metrics in a supply chain environment. Int. J. Ops Prod. Mgmt, 2001, 21(1-2), 71-87.

15 Hausman, W. H. Supply chain performance metrics. In The practice of supply chain management: where theory and application converge, 1st edition (Eds T. P. Harrison, H. L. Lee, and J. J. Neale), 2003, 61-76 (Springer-Verlag, Berlin). 
16 Tracey, M., Lim, J. S., and Vonderembse, M. A. The impact of supply-chain management capabilities on business performance. Supply Chain Mgmt: Int. J., 2005, 10(3), 179-191.

17 Day, G. S. The capabilities of market-driven organizations. J. Marketing, 1994, 58(4), 37-52.

18 Lee, W. B., Cheung, H. C. W., Choy, L., and Choy, K. L. Development of a web-based enterprise collaborative platform for networked enterprises. Business Process Mgmt. J., 2003, 9(1), 46-58.

19 Holmberg, S. A system perspective on supply chain measurement. Int. J. Phys. Distribution Logistics, 2000, 30(10), 847-868.

20 Lummus, R. R. and Vokurka, R. J. Managing the demand chain through managing the information flow: capturing 'moments of information'. Prod. Inventory Mgmt J., 1999, first quarter, 16-20.

21 Ireland, R. and Bruce, R. CPFR: only the beginning of collaboration. Supply Chain Mgmt Rev., September-October 2000, 80-88.

22 Busi, M. and Bititci, U. C. Collaborative performance management: present gaps and future research. Int. J. Productivity Performance Mgmt, 2006, 55(1), $7-25$.

23 Macbryde, J. C. and Mendibil, K. Designing performance measurement systems for teams: theory and practice. Mgmt Decision, 2003, 41(8), 722-733.

24 Lambert, D. M. and Pohlen, T. L. Supply chain metrics. Int. J. Logistics Mgmt, 2001, 12(1), 1-19.

25 Flanagan, J. C. The critical incident technique. Psycholog. Bull., 1954, 1, 327-58.

26 Gummesson, E. Qualitative methods in management research, 2000 (Sage Publications, London).

27 Bitner, M. J., Booms, B. H., and Tetreault, M. S. The service encounter: diagnosing favourable and unfavourable incidents. J. Marketing, 1990, 54(1), 71-84.

28 Patton, M. Q. Qualitative research and evaluation methods, 3rd edition, 2002 (Sage Publications, London).

29 Boyd, C. O. Phenomenology, the method. In Nursing research: a qualitative perspective, 3rd edition (Ed. P. L. Munhall), 2001, 99-132 (Jones and Bartlett, Sudbury, Massachusetts).

30 Groenewald, T. A phenomenological, research design illustrated. Int. J. Qualitative Methods, 2004, 3(1), Article 4

31 Creswell, J. W. research design: qualitative, quantitative, and mixed method approaches, 2nd edition, 2003 (Sage Publications, London).

32 Robson, I. and Rawnsley, V. Co-operation or coercion? Supplier networks and relationships in the UK food industry. Supply Chain Mgmt: Int. J., 2001, 6(1), 39-47.

33 Lawrence, F. Farmers still exploited by big retailers. Guardian, 17 March 2003.

34 Fletcher, R. The supermarkets' code of malpractice. Telegraph, 28 September 2003.

35 Wincell, J. Competitive partnerships. Optimize, August 2002, (10). Available online www.optimizemag.com.

36 Rigsbee, E. Partnershift: how to profit from partnering trend, 2000 (John Wiley, New York).
37 McClenahen, J. S. Ford and Firestone separation: not just about tires. www.industryweek.com., online article published on 30 May 2001.

38 Supermarkets: a report on the supply of groceries from multiple stores in the United Kingdom ( $\mathrm{Cm}$ 4842), 2000, (HMSO, London).

39 Miles, M. B. and Huberman, A. M. Qualitative data analysis: an expanded sourcebook, 1994 (Sage Publications, Thousand Oaks, California).

40 Dani, S. and Burns, N. D. Logistics research network conference. In Proceedings of the Logistics Research Network Sixth Annual Conference, Heriot-Watt University, Edinburgh, 13 September 2001, pp. 111-117 (The Chartered Institute of Logistics and Transport (UK), London).

41 Dani, S. and Burns, N. D. Supply chain relationships. In Proceedings of the UK Symposium on Supply chain alignment, Liverpool, July 2001, pp. 84-100.

42 Cox, A., Sanderson, J., and Watson, G. Power regimes: a new perspective on managing in supply chains and networks. In Tenth International Annual International Purchasing and Supply Education and Research Association Conference, Jonkoping, Sweden, 2001. Available online www. ipsera.com.

43 Hirschman, A. O. Exit, voice and loyalty response to decline in firms, organizations and states, 1970 (Harvard Paperback, Cambridge, Massachusetts).

44 Helper, S. An exit-voice analysis of supplier relations. In The embedded firm (Ed. G. Grabher) 3rd reprint, 1993, 141-160 (Routledge, London).

45 Mischel, W. The interaction of person and situation. In Personality at the crossroads: current issues in interactional psychology (Eds. D. Magnusson and N. Endler), 1977, Ch. 25 (Lawrence Erlbaum Associates, Mahwah, New Jersey).

46 Mullins, J. W. and Cummings, L. L. Situational strength: a framework for understanding the role of individuals in initiating proactive strategic change. J. Oganisational Change Mgmt, 1999 12(6), 462-479.

47 Harland, C. M. Supply chain management: relationships, chains and networks. Br. J. Mgmt, March 1996, 7, S63-S80.

48 Cox, A., Ireland, P., Lonsdale, C., Sanderson, J., and Watson, G. Supply chains, markets and power: mapping buyer and supplier power regimes, 2002 (Routledge, London).

49 Dani, S. and Burns, N. D. Developing a framework based on a psychological perspective for studying buyer-supplier relationships. In Internet-based enterprise integration and management, Proceedings of SPIE, Vol. 4566, 2001, Paper 4566-04 (SPIE, Bellingham, Washington).

50 Ackroyd, S. and Thompson, P. Organizational misbehaviour, 1998 (Sage Publications, London).

51 Berne, E. Games people play: psychology of human relationships, 1964 (Grove Press, New York).

52 Stewart, I. and Joines, V. TA today: a new introduction to transactional analysis, 1999 (Lifespace Publishing), Reyworth, Leicestershire, reprint. 
53 Dani, S., Backhouse, C. J., and Burns, N. D. Application of transactional analysis in supply chain networks: a potential holonic mediating tool. Proc. Instn Mech. Engrs, of Part B: J. Engineering Manufacture, 2004, 218(B5), 571-580.

54 Dani, S., Backhouse, C. J., and Burns, N. D. Buyer-Supplier behaviour in electronic reverse auctions: a relationships perspective. Int. J. Services Ops Mgmt, 2005, 1(1), 22-34.
55 Dani, S., Burns, N. D., and Backhouse, C. J. Modeling voice and exit strategies within industrial network relationships. In Proceedings of the 2002 IEEE International Engineering Management Conference, Cambridge, UK, 18 August 2002, pp. 264-269, (IEEE, New York).

56 Jap, S. D. Perspectives on joint competitive advantages in buyer-supplier relationships. Int. J. Res. Marketing, 2001, 18, 19-35. 